\title{
Como um Harém pode mudar tudo: reflexões sobre o teatro no Piauí, em diálogo com Airton Martins
}

How a Harem can change everything: reflections about theater in Piauí, in dialogue with Airton Martins

Entrevista concedida à Erica

Rodrigues Fontes ${ }^{1}$ 


\section{Resumo}

Airton Martins fala, em entrevista a seguir, sobre sua experiência teatral e depois discorre sobre a trajetória do grupo Harém de Teatro (PI), do qual é um dos fundadores. Narra também como a história do grupo está intimamente ligada a uma dinamização cultural na região e à divulgação artística do estado do Piauí no Brasil e no mundo.

Palavras-chave: Teatro piauiense; história do teatro; grupo teatral

\section{Abstract}

Airton Martins talks, in the following interview, about his theatrical experience and later elaborates on the trajectory of the Harém de Teatro group (from Piauí state, Brazil), of which he is one of the founders. He also narrates how the history of the group is intimately connected to a cultural dynamization of the region and to an artistic promotion of the state of Piauí in Brazil and around the globe.

Keywords: Piauiense Theater; theatrical history; theater group 


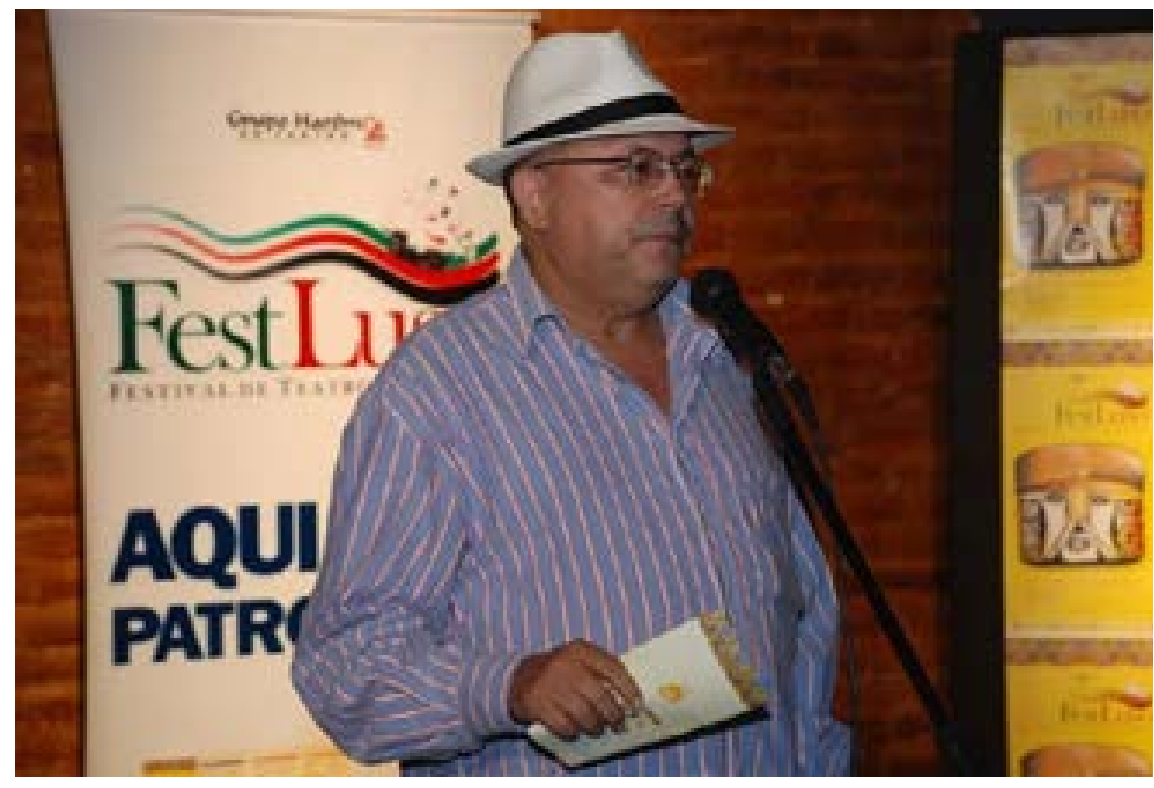

Airton Martins presidente do Grupo Teatral Harém, Teresina (PI).

Foto: Margareth Sales Leite

A Considerado, com frequência, como sendo um dos estados mais pobres do Brasil, o Piauí e sua arte resistem bravamente, embora com pouco (ou quase nenhum) incentivo governamental. No campo teatral, destaca-se o grupo Harém de Teatro, existente desde 1985 e que assume liderança no cenário cultural regional, nacional e internacional, atuando também como Ponto de Cultura, no espaço Nos Trilhos do Teatro, antiga estação de trem desativada que hoje funciona como sede do grupo e local de várias apresentações culturais. Em 2008, o grupo lançou o FestLuso, Festival de Teatro que reúne grupos de países lusófonos. Em sua sexta edição (de 24 a 30 de agosto de 2015) o evento contou com a presença de grupos do Brasil (Teresina, São Paulo, Rio de Janeiro, Recife e Salvador), Portugal, Moçambique, Angola, Cabo Verde e China (Macau).

Em 2014 iniciei documentação sobre as atividades do grupo Harém, ligada à minha pesquisa acadêmica "Vozes oprimidas", sobre minorias políticas e ditadura militar no Brasil. A pesquisa, ainda em andamento, contou até julho de 2015 com o trabalho da bolsista Tarciana Gomes (aluna de Comunicação Social da UFPI - bolsista PIBIC/ CNPQ). A documentação das ações do grupo torna-se de suma importância porque, até agora, ele apresenta a maior produção teatral/cultural já registrada no estado, mas que não possui um registro documental por escrito, ou ainda, impresso. Como resultado da pesquisa deve ser publicado o livro Como um harém mudou o Piauí: inserções culturais através do teatro (título provisório).

O grupo Harém de Teatro surgiu no ano de 1985, estreando seu primeiro espetáculo na Semana Chico Pereira², com a peça $O$ trágico destino de duas Raimundas ou Os dois amores de Lampião antes de Maria Bonita e só agora revelados, de Chico Pereira. A formação inicial do grupo contava com Arimatan Martins, Airton Martins,

${ }^{2}$ A Semana Chico Pereira ocorreu em 1985 e encenou peças deste dramaturgo piauiense, em homenagem a sua obra. 
Francisco Pellé, Thais Campos, Adriana Müller, Pinho Gondinho e Augusto Neto, considerados assim, portanto, fundadores do grupo.

De 1985 a 2009 o grupo realizou 16 montagens, sempre valorizando os autores locais como Gomes Campos e Chico Pereira. Dessas montagens, houve participação em 38 festivais locais, nacionais e internacionais, a exemplo do XVI Festival de Inverno de Campina Grande (PB) em 1986, do Festival de Teatro de Erechim (RS), e da 4a Edição da Sementes Mostra Internacional de Teatro Para o Pequeno Público, em Almada - Portugal, em 1999. Dentre estes, o número de premiações é bastante relevante, dando reconhecimento ao grupo até mesmo internacionalmente, contabilizando mais de 50 premiações, em diversas categorias. Como destaque temos o recebimento, pelo grupo, do Prêmio de Mérito Lusófono, concedido pela Fundação Luso-Brasileira Para o Desenvolvimento da Língua Portuguesa no Mundo/ Ministério da Cultura de Portugal (1997) e das premiações para melhor ator-coadjuvante e melhor figurino no XI Festival Nacional de São Mateus (FENATE) - ES e para melhor ator-coadjuvante e melhor iluminação no V Festival Nordestino de Guaramiranga (CE), em 1998.

O Grupo Harém também é responsável pela formação artística de muitos atores piauienses. Criada ainda na década de 1980, a oficina de teatro Procópio Ferreira foi, por muitos anos, a única forma de estudo do teatro no estado, visto que, ainda hoje, há apenas a Escola Técnica de Teatro Gomes Campos ${ }^{3}$, que passa por grandes dificuldades estruturais e financeiras. Inicialmente, a oficina era administrada pelo ator e diretor Arimatan Martins, um dos fundadores do Grupo Harém, e atualmente é administrada pelo ator e diretor Luciano Brandão.

Hoje, o Harém é grupo que referencia o teatro piauiense fora do estado, dando à localidade uma visibilidade antes ínfima. As muitas dificuldades, principalmente financeiras, não limitaram o grupo que produz peças e viaja com recursos próprios. Para a pesquisa, entrevistamos um de seus fundadores: o ator e presidente do grupo, Airton Martins.

\section{Erica Rodrigues Fontes - Airton, como foi iniciada a sua relação com o grupo Harém?}

Airton Martins - Eu sou ator, iniciei minha atividade teatral na cidade de Floriano (Piauí), com 15 anos de idade em um grupo de teatro de jovens ligados à igreja católica. Na minha época de adolescente, era mais voltado para as comédias, porque atraía mais público. Então a gente selecionava aquelas comédias cearenses de Pedro Bloch e montava. Encenamos quase todas as peças de criança de Maria Clara Machado: as crianças eram um dos públicos-alvo. E aí em meado da década de 1970, eu e o Arimatan Martins, meu irmão, viemos para Teresina estudar. Ele queria estudar medicina e eu já queria mesmo fazer teatro. Vimos que não seria fácil. $O$ teatro do Piauí andava a passos lentos. Observamos que Santana e Silva, Gomes Campos,

\footnotetext{
${ }^{3}$ A única escola técnica de teatro do Piauí é mantida pela Secretaria Estadual de Cultura do estado e oferece vagas gratuitas para o estudo das Artes Cênicas. $O$ curso técnico dura um ano e meio.
} 
Tarcísio Prado, José da Providência - grandes nomes do teatro piauiense - estavam iniciando e passavam por momentos difíceis naquela época, porque não existia uma escola em Teresina. Era difícil juntar pessoas para montar um grupo. Aí em 1976 João das Neves veio ao Piauí e foi professor do Ari [Arimatan], que se tornou seu assistente de direção no Rio de Janeiro, depois de formado pela CAL [Casa das Artes de Laranjeiras]. Fizemos vários espetáculos e depois paguei pelos estudos teatrais de Arimatan no Rio de Janeiro. Ele retornou já montando um espetáculo, porque tinha dificuldade até pra encontrar um ator jovem para fazer O Princês do Piauí, de Benjamim Santos, com direção de Tarcísio Prado. Eu era ator e produtor desse espetáculo. E nós estreamos no dia 4 de setembro de 1976, no aniversário do Teatro 4 de Setembro [mais antigo e principal teatro de Teresina, localizado no centro da cidade]. Para a Semana Francisco Pereira da Silva, Tarcísio Prado decidiu montar Os dois amores de Lampião antes de Maria Bonita e só agora revelados, com direção do Arimatan Martins. Nessa peça eu fazia o personagem principal, o Lampião. Da semana de Chico Pereira surgiu a ideia de criarmos um grupo de teatro, o Harém, um divisor de águas no teatro do Piauí. O nome Harém vem de uma brincadeira nossa, porque o Lampião era possuidor de um harém. Até hoje o nome é Harém. Depois nós começamos a montar outros espetáculos, para trazer para Teresina a história de Chico Pereira.

\section{Erica Rodrigues Fontes - E era fácil o acesso a Chico Pereira?}

Airton - Pelo contrário. Queríamos mostrar para o piauiense quem foi Chico Pereira ${ }^{4}$, um dos autores mais montados do Rio de Janeiro na década de 1940 e 1950 e até o início dos anos $1960^{5}$. Ele foi crítico de jornal, crítico de teatro, escrevia muito também, mas era um cara muito introspectivo. Trabalhava na Biblioteca Nacional. Os diretores tinham que ir atrás dele para conseguir acesso aos textos. Na época ele era mais conhecido no Rio do que no Piauí. Quando Chico veio ao Piauí e viu a nossa montagem para a peça do Lampião disse que estávamos autorizados a montar todas as suas peças. Depois disso tivemos problemas com a família dele que queria cobrar direitos autorais.

\section{Erica Rodrigues Fontes - E como essa autorização influenciou o trabalho do grupo?}

Airton - Muitos atores começaram a querer trabalhar conosco no teatro e passar por treinamento conosco. A nossa ideia na hora era a de criar um núcleo de Artes Cênicas no Teatro 4 de Setembro, para formação de atores. Depois Bibi Ferreira veio

\footnotetext{
${ }^{4}$ Francisco das Chagas Pereira da Silva - 1918 (PI) -1985 (RJ) - nasceu em Campo Maior, Piauí. Em 1942 mudou-se para o Rio de Janeiro onde fez carreira como funcionário da Biblioteca Nacional e como dramaturgo.

5 "A primeira peça do dramaturgo Francisco das Chagas Pereira da Silva a ser montada foi Lazzaro em 1952; premiada pela Associação Brasileira de Críticos Teatrais. Seu texto mais conhecido e com maior número de montagens é Chapéu de Sebo (1961), encenada também na Alemanha, na antiga Tchecoslováquia e na Finlândia, permanecendo em cartaz por vários anos". Em 2010 a Funarte publicou a obra completa de Francisco Pereira da Silva, em 3 volumes, organizados por Virgílio Costa. Nestas obras constam 32 peças deste dramaturgo. Coleção Teatro Completo - Francisco Pereira da Silva - Volumes I, II e III. Organização de Virgílio Costa. A maioria de sua obra permanece inédita. "Um dia, Chico decidiu sair de cena e não mais escrever para o teatro, e voltou-se para a prosa de ficção. Autor festejado pela crítica, suas montagens foram ignoradas pelo público". Dados obtidos em: http://www.funarte.gov.br/literatura/dramaturgo-francisco-pereirada-silva-tem-obra-completa-editada-pela-funarte/\#ixzz3xiuzexO3
} 
aqui cantando Piaf, em uma produção que eu fiz. Resolvemos, então, homenagear o pai dela colocando o nome dele na escola que ficaria sob nossa responsabilidade. O Procópio [Ferreira] era um homem que viajava por todo o Brasil com teatro, fez discurso no [teatro] 4 de Setembro. Tem isso gravado. É muito bonito. Ele falava do abandono do teatro. Sempre foi contestador.

Erica Rodrigues Fontes - Em 27 de dezembro de 2008 fui a uma peça da Bibi Ferreira no Rio de Janeiro, Às favas com os escrúpulos, escrita por Juca de Oliveira. Ao final, conversei com Bibi sobre o Piauí e o teatro daqui, mencionei o Harém e ela ficou muito feliz. Lembrouse do grupo e demonstrou imenso carinho. Depois a assessora dela veio falar comigo sobre a relação dela com o grupo e disse que viriam ao Piauí. Observei que na memória dela [Bibi] o estado do Piauí é muito vivo.

Airton - Fiquei arrepiado agora que você falou da Bibi. Eu fiz muita força para trazer a Bibi Ferreira ao Piauí, porque trazer qualquer espetáculo grandioso é muito caro. Você pensa numa produção de 100 mil reais para ter um retorno de bilheteria de 20 mil, 25, 30 mil reais. Então, em qualquer produção grande, produção que você vai fazer aqui, você conta logo com o prejuízo. As pessoas nunca querem pagar. Só querem ir convidadas...

\section{Erica Rodrigues Fontes - Essa questão do patrocínio continua sendo um desafio, não é?}

Airton - Se você tem boas relações ainda consegue alguma coisa. No caso do espetáculo da Bibi Ferreira, eu não tive prejuízo. Mas também não tive lucro. Regina Duarte [com quem o grupo mantém relacionamento próximo desde os anos 1970] viu a peça Raimunda Pinto e decidiu que queria comemorar seus cinquenta anos de carreira com o espetáculo. Queria fazer com o Harém. Ela substituiria o Pellé [que sempre faz a protagonista]. Não funcionou porque Hermes Frederico, produtor do espetáculo e coordenador da CAL, preferiu trabalhar com os alunos dele [da CAL], em vez de levar atores do Piauí, porque sairia mais barato.

Erica Rodrigues Fontes - Como é, praticamente, a questão de formação de atores no Piauí através do Harém?

Airton - A oficina Procópio Ferreira foi criada por nós [do Harém] quando eu era o diretor geral do Teatro 04 de setembro, o Pellé era o diretor administrativo e o Arimatan o diretor artístico. Foi a oportunidade que os artistas jovens de Teresina tiveram pra fazer teatro. Franklin Pires, Bid Lima, Laiene Holanda, Elielson Vasconcelos, Marcelo Julian, Maneco Nascimento, Jorge Carlo e os novos atores do Piauí da época passaram por essa escola.

Pellé - [ator do grupo, ouve a conversa e contribui]: A escola não tem algo fe- 
chado, uma grade curricular, vê a necessidade do aluno e tenta trabalhar com isso.

Airton - Mas, sem dúvida alguma, o Arimatan foi quem mais contribuiu com formação de atores no Piauí. O Aderbal Freire Filho dirige o ator e você vê o ator em cena. O Arimatan é dessa escola. Então, todo mundo que trabalha com o Arimatan sente que amadurece como ator.

Erica Rodrigues Fontes - Vocês não têm medo, por exemplo, daqui a 20 anos de não ter ninguém para assumir o papel de vocês, culturalmente? Como eu tenho essas perguntas às vezes sobre a MPB, sabe, por exemplo, Chico Buarque envelhecendo muito, não produzindo/ compondo mais tanto, quem assume? Essa preocupação quanto ao papel do Harém nunca passou pela cabeça de vocês, não?

Airton - Isso é muito perigoso, principalmente no teatro. Eu não conheço diretores como Arimatan Martins aqui no Piauí. Arimatan é destacado, de longe, o homem que mais sabe fazer teatro no Piauí. E isso me preocupa. No próprio Harém, não há um sucessor do Arimatan. Nós agora estamos com a ideia de fazer um espetáculo dirigido pelo Pellé. Mas com assistência do Arimatan. Meu compadre Tarcísio Prado está vivo, mas não está mais produzindo. Pra você ter uma ideia, eu sou o ator mais velho em atividade do Piauí. Um cara com 60 anos de idade.

\section{Erica Rodrigues Fontes - Não se acha muito novo, não, para ser o mais velho em atividade?}

Airton - É um absurdo, isso.

\section{Erica Rodrigues Fontes - Falamos de Bibi que hoje já tem 94 anos e ainda canta e atua. É uma grande diferença, não acha?}

Airton - E a Bibi ainda é diva no palco, né? Aqui os artistas se aposentam muito cedo, se afastam muito cedo do teatro. Isso me preocupa muito. E eu como fundador, presidente e participante do Harém, me preocupo muito com isso. Acho que está na hora de a gente trazer mais pessoas para o Harém, usar muito o nome, a força que o Harém tem pra produzir espetáculos com outras direções. Eu não sei como nossos atores do Harém vão se comportar com outro tipo de direção, porque o Arimatan começa o espetáculo desmontando o espetáculo, desnudando o espetáculo. Depois é que remonta. Quando você pensa que não, o espetáculo está pronto, e em $90 \%$ das nossas montagens, ninguém sabe nem o que vai fazer e nem o que o outro vai fazer. A gente começa, toca a bola até sair o espetáculo pronto. De repente você está vestido no personagem e se identifica. O Harém sempre foi assim. Com nossa montagem de Raimunda Pinto foi assim. Até chegar ao Pellé, passaram várias meninas pelo Harém, tentando fazer a Raimunda Pinto. E depois foi ele que ficou com o papel.

\section{Erica Rodrigues Fontes - Então foi o Pellé que mais se identificou}




\section{com o personagem?}

Airton - Sim, e esse foi o personagem que projetou o Pellé pro Brasil, não só para Teresina. O Pellé hoje é um ator conhecido nacionalmente. Ele é referência em qualquer lugar que você chegue no Brasil. O Harém participou dos festivais de teatro que eram patrocinados pela FUNARTE, na época a patrocinadora dos grandes festivais nacionais de teatro do Brasil. Havia o Festival Nacional de Campina Grande e festivais no Paraná, em São José do Rio Preto, também em Florianópolis. Em qualquer festival no Brasil nos anos 1990 e começo dos anos 2000, quando o Harém chegava, era uma festa! "Piauí! Piauí chegou”, diziam. Era assim. Mas eu concordo com o Pellé.

\section{Erica Rodrigues Fontes - Quando diz que o grupo não traduz o Piauí, necessariamente?}

Airton - Não traduz o Piauí, porque a gente mexia muito pouco com apoio governamental, a gente sempre lutou e participou das coisas com as nossas próprias pernas e com o nosso próprio bolso. Em algumas viagens fazíamos assim: eu fazia um crediário de 9 passagens no meu nome, o Arimatan comprava mais 9 e íamos pra São Paulo, entendeu? Depois a gente decidia como pagava. Era assim que se viajava, assim que se fazia as coisas, por isso que o Pellé tem esse ressentimento de dizer que não quer representar ou dizer que o Harém não representa o teatro do Piauí. Mas a referência do teatro do Piauí é o Harém. Pela participação que nós tivemos em vários locais...

\section{Erica Rodrigues Fontes - Nenhum outro grupo do Piauí teve tanta visibilidade como o Harém fora do Piauí?}

Airton - Não. Porque a gente tinha o grupo teste, por exemplo, ele [grupo teste] participou com $O$ auto do Lampião do além, de Gomes Campos, em 1966 no Festival do Estudante no Rio de Janeiro, prêmio Negrão de Lima, quando o Tarcísio Prado ganhou o prêmio de ator coadjuvante. Então o Harém é o grupo mais premiado da história do teatro no Piauí. Temos mais de 50 prêmios nacionais. Isso foi bom porque abriu muitas portas. A gente participava em um ano e, no próximo ano, já tinha a preocupação de levar outra companhia do Piauí. Nós participamos do primeiro Festival de Guaramiranga, com a Raimunda Pinto. Ganhamos todos os prêmios do festival, menos atriz. Nesse primeiro festival, nós ganhamos 7 prêmios dos 9 possíveis, porque não tínhamos mulheres no elenco da Raimunda Pinto, então prêmios para atriz e atriz coadjuvante nós não podíamos receber. E o Pellé ganhou [prêmio] de melhor ator. Isso também abriu as portas para outras companhias do Piauí participarem tanto de Guaramiranga como dos festivais nacionais onde nós estivemos presentes com grandes espetáculos. 


\section{Referências}

CAMPELO, Ací. História do teatro piauiense. Teresina, PI: Assessoria e Promoções Culturais, 2010.

SILVA, Francisco Pereira da. Raimunda, Raimunda. Teresina: Grupo Harém de Teatro, 2008.

http://festluso.blogspot.com.br/p/grupo-harem.html (Acesso em 29 de janeiro de 2016)

http://www.memorialdeartescenicas.com.br/site/teatro-c2/116-grupo-harem-deteatro.html (Acesso em 29 de janeiro de 2016)

Recebido em: 02/11/2015

Aprovado em: 02/02/2016

Recebido em: 30/01/2016

Aprovado em: 05/02/2016 